\title{
Expresiones del "trabajo decente". en la jurisprudencia del Tribunal Constitucional
}

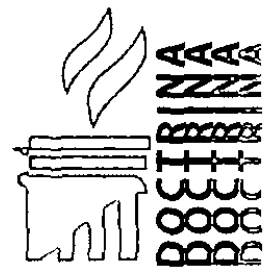

\section{Carlos Cornejo Vargas}

Abogado por la Pontificia Universidad Católica del Perú. Magister en Derecho del Trabajo y Seguridad Social por la Pontificia Universidad Católica del Perú. Especialista en Derecho del Trabajo y de la Seguridad Social.

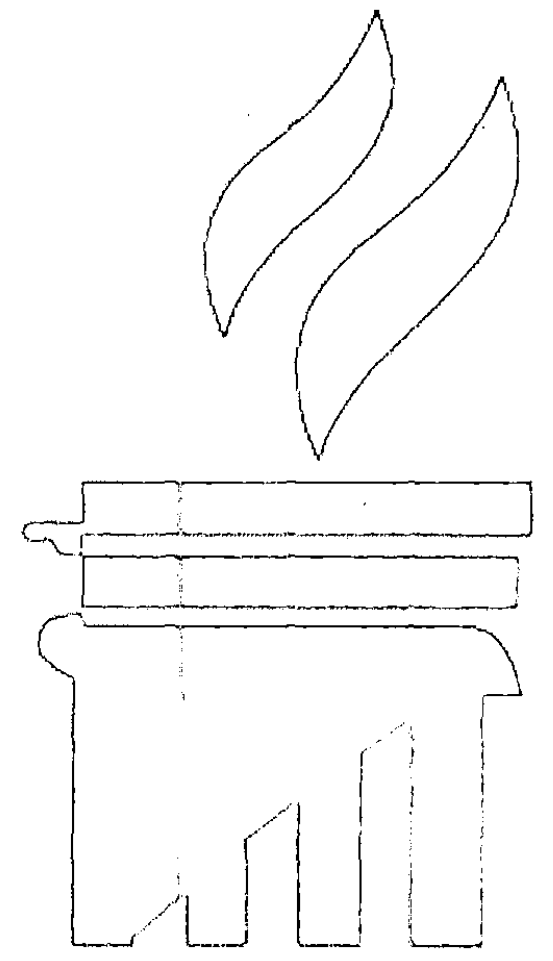

SUMARI0:

I. Introducción.

II. Marco teórico:

1. Alcances conceptuales;

2. Dimensiones del trabajo decente;

3. Trabajo decente y pobreza;

4. Naturaleza jurídica.

III. Los derechos inespecificos laborales y su relación con el trabajo decente.

IV. Concepto de "trabajo decente" como sustento de las resoluciones emitidas por el Tribunal Constitucional.

V. El tratamiento de la jornada de trabajo en la jurisprudencia del Tribunal Constitucional.

VI. El tratamiento del derecho de igualdad en la jurisprudencia del Tribunal Constitucional.

VII. El Tratamiento de los derechos de sindicación y negociación colectiva en la jurisprudencia del Tribunal Constitucional.

VIII. Las otras dimensiones del trabajo decente en la jurisprudencia del Tribunal Constitucional.

IX. Conclusiones. 


\section{INTRODUCCIÓN}

A partir del nuevo escenario económico mundial y con la finalidad de enfrentarlo, hace algunos años la Organización Internacional del Trabajo (OIT) creó y acuñó el concepto de "Trabajo Decente" $y$ desde ese momento se ha concentrado en la realización de actividades para el desarrollo teórico y práctico del mismo.

A nivel teórico ha trabajado literatura que explique los alcances del tema, sus objetivos y las metas que deberían alcanzarse como consecuencia de su implementación.

A nivel práctico ha llevado el tema a la discusión en distintos foros a efectos de explicar sus alcances y de lograr que los Estados miembros de la OIT modifiquen su legislación interna para adecuarla al contenido del concepto de "Trabajo Decente" en busca del respecto y vigencia de los derechos en el trabajo, de la seguridad laboral y del dialogo social, etc.

En vista de los avances sobre el tema y de la preocupación del Estado peruano por sentar las bases para la generación de "Trabajo Decente", creemos que es importante revisar el comportamiento del Tribunal Constitucional frente al concepto antes mencionado, a efectos de conocer si lo ha incorporado en sus pronunciamientos y cómo ha enfocado y desarrollado algunos de los derechos laborales que integran el catálogo de derechos que son expresión del "Trabajo Decente".

\section{MARCO TEÓRICO}

El desarrollo del comercio internacional y la movilización de capitales son las características principales del contexto económico mundial y del fenómeno denominado "Globalización", el cual presenta dos (2) frentes, pues ha traido ventajas y desventajas, beneficios y perjuicios, etc.

En efecto, entre las ventajas podemos mencionar al aumento de la producción de bienes y servicios, lo que ha generado un círculo virtuoso, pues la mayor producción ha generado mayor riqueza $y$, por ende, mayor demanda lo que a su vez ha generado una reactivación económica que ha explotado casi a nivel mundial, aunque especialmente en los países desarrollados.

No obstante lo anterior, también hay desventajas, pues lamentablemente la reactivación económica antes mencionada solo ha alcanzado a los países que estaban en capacidad de responder a las exigencias que planteó la mayor intensidad del intercambio internacional, habiendo incluso excluido a aquellos paises que no estaban en condiciones de hacer frente al nuevo escenario económico mundial.

Ciertamente, si bien es exacto que la globalización ha generado un aumento de la riqueza a nivel mundial, no lo es menos que el referido aumento no ha sido equitativo, antes bien, ha sido inequitativo, pues ha hecho más"ricos"a los países ricos y más "pobres" a los países pobres.

Siendo específicos, cabe señalar que si la globalización ha implicado una revolución tecnológi$c a$ también ha significado una revolución del mercado de trabajo, pues mientras mayor es el avance tecnológico, es menor el requerimiento de trabajadores. De acuerdo con lo anterior, es posible afirmar que la globalización además de haber generado riqueza, también ha generado pobreza, y con ella, desempleo y sub-empleo.

En respuesta a la situación descrita, la Organización Internacional del Trabajo (OIT) advirtió la necesidad de hacer algo para evitar, cuando menos limitar, los efectos perniciosos generados por la globalización.

Ese es el contexto en el que surge el concepto de "Trabajo Decente".

\section{Alcances Conceptuales}

El concepto de "Trabajo Decente" tiene su partida de nacimiento en el año 1999, y en la Memoria de la 87 Conferencia Internacional del Trabajo, documento en que el apareció como un tema nuevo y de contenido incierto y poco definido. 
En efecto, en la Memoria del Director General a la Conferencia Internacional del Trabajo de 1999, aparece una primera y preliminar definición, la misma que lo conceptualiza como trabajo productivo en condiciones de libertad, equidad, seguridad y dignidad, en el cual los derechos son protegidos y que cuenta con remuneración adecuada y protección social.

No obstante lo anterior, y por tratarse de una nueva construcción teórica, en otros documentos, el Director General de la OIT ensayó nuevas definiciones análogas a las antes referidas, que ratifican algunos elementos, subrayan otros $y$ añaden otros más.

Así, por ejemplo, señala que "(...) por trabajo decente se entiende el trabajo que se realiza en condiciones de libertad, equidad, seguridady dignidad humana" (sic).

Al respecto, Oscar Ermida, destacado laboralista uruguayo refiriéndose al concepto de "Trabajo Decente" ha señalado que "Dada la ausencia de antecedentes (...) puede ser visto como un 'slogan' carente de contenido definido, o como un concepto integratorio que involucra objetivos, valores y politicas o como un concepto dinámico" (sic). ${ }^{2}$

Coincidimos con el profesor Ermida, pues en 1999, solo se conocía el problema que debía ser enfrentado y combatido, y no la solución al mismo, aunque se tenía alguna idea de ella, la cual iba a ser modificada en el tiempo con los aportes y ajustes realizados por los estudiosos y especialistas en el tema.
Reforzando lo anterior, el mismo profesor Ermida ha señalado que "(...) se trata de un concepto en construcción, de profundo contenido ético y que tiende a resaltar la importancia de los derechos del trabajador y de la calidad de las condiciones de trabajo. El trabajo decénte no puede ser sino el trabajo en cantidad y calidad suficientes, apropiadas, dignas y justas, lo que incluye el respeto de los derechos, ingresos y condiciones de trabajo satisfactorias, protección social y un contexto de libertad sindical y diálogo social" (sic) (el subrayado es nuestro). ${ }^{3}$

Por lo expuesto, podemos concluir, por lo menos parcialmente, que estamos ante un concepto preliminar y provisional, en construcción, de carácter integrativo y de profundo contenido ético.

Complementando lo anterior, cabe señalar que al principio no había definición jurídica, por lo que se debió recurrir al lenguaje común y coloquial, en virtud del cual se entiende que "decente" es suficiente, justo, digno, adecuado y a partir de ello cada sociedad construye su propio concepto de "Trabajo Decente".

En efecto, "Cada sociedad comprenderá a su manera en que consiste el trabajo decente, por lo tanto la definición precisa deberá estar relacionada a las condiciones que prevalecen en cada país en particular" (sic). ${ }^{4}$

No obstante lo expuesto, teniendo en cuenta el tiempo transcurrido desde la creación del concepto en el año 1999, y el común denominador

1 SOMAVIA, Juan, Un trabajo decente para todos en una economía globalizada: una perspectiva de la OIT, Documento presentado a la Tercera Conferencia Ministerial de la OMC, Diciembre, 1999.

2 SOMAVIA, Juan, Un trabajo decente para todos en una economía globalizada: una perspectiva de la OlT, Documento presentado a la Tercera Conferencia Ministerial de la OMC, Diciembre, 1999.

3 ERMIDA URIARTE, Oscar, Trabajo Decente y Formación Profesional, Cinterfor, Montevideo, 2001. En: BARRETO GHIO$\mathrm{NE}$, Hugo, Concepto y dimensiones del trabajo decente: entre la protección y la participación de los trabajadores en la empresa, Revista Derecho Laboral, No. 204, Montevideo, 2001.

4 EGGER, Philippe y SENGENBERGER, Werner, Problemas y políticas del trabajo decente, Boletín No. 151, Trabajo Decente y Formación Profesional, Cinterfor, Montevideo, 2001.

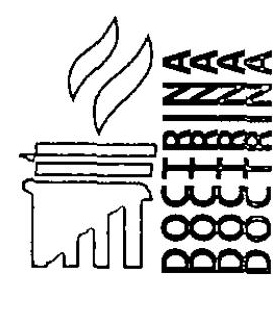


que significa el respeto de la dignidad humana, es posible afirmar con convicción y sin temor de incurrir en un error que el trabajo decente "implica acceder $a$ un empleo en condiciones de libertad, de reconocimiento de derechos básicos al trabajo que garantizan que no haya discriminación ni hostigamiento en el trabajo, que se reciba un ingreso que permita satisfacer las necesidades básicas económicas, sociales y familiares, y que se logre un nivel de protección social para el trabajador y los miembros de su familia, así como el derecho de expresión y participación laboral, directa o indirectamente a través de organizaciones representativas elegidas por el mismo" (sic). ${ }^{5}$

Complementando lo expuesto, es preciso tener en cuenta que la doctrina guarda consenso y es uniforme cuando se trata de reconocer que el "Trabajo Decente" juega un rol de singular importancia en la realización personal de los individuos y, simultáneamente, de las sociedades.

En este sentido, es necesario reconocer que el trabajo permite a la persona acceder a un ingreso, favorece su integración social y el autoreconocimiento personal, lo que en definitiva, permite la cohesión de la sociedad.

Sin embargo, el trabajo también puede ser un factor de exclusión, pues si a diferencia de la situación descrita precedentemente, no asegura la percepción de un ingreso que le permita satisfacer las necesidades humanas y sociales básicas, fomentará la sumisión y marginalización.

A partir de las consideraciones precedentemente expuestas, resulta que el "Trabajo Decente" es una expresión de cómo los individuos y la gente común percibe su presente y su futuro laboral; de cómo ve sus actuales condiciones de trabajo; de cómo equilibra su vida laboral y familiar; de cómo se consigue la igualdad de género; de cómo uno puede expresarse y ser escuchado; etc. En suma, el "Trabajo Decente" persigue el respeto de la dignidad humana. ${ }^{6}$

Así pues, es claro que el "Trabajo Decente" se define en función de las aspiraciones básicas de los trabajadores, entre las cuales podemos mencionar las siguientes: acceso al empleo; trato justo y equitativo; remuneración justa; condiciones laborales adecuadas; ambiente de trabajo seguro; protección en caso de desempleo; protección de seguridad social en salud; formación y capacitación; participación y motivación; y participación colectiva.

Como bien apunta, Philippe Egger y Werner Sengenberger "La combinación de todas o algunas de estas diez dimensiones pueden conformar el concepto de trabajo decente para todos los hombres y mujeres. La combinación y la ponderación otorgada a cada una dependerá de las circunstancias particulares del país, la región y la empresa" (sic).?

Luego, en función de las consideraciones expuestas consideramos que el "Trabajo Decente" es aquel que se genera basado en el principio de causualidad (a plazo indefinido o temporal); que se ejecuta en una jornada razonable; que se remunera de manera adecuada; en el que se reconocen derechos (a horas extras, descanso semanal, vacaciones, etc.); que se ejecuta en un ambiente de trabajo seguro y saludable; que se ejecuta con cobertura previsional y de salud; y que autoriza al ejercicio pleno de los derechos colectivos (sindicación, negociación colectiva y huelga).

\section{Dimensiones del Trabajo Decente}

Como ya ha quedado dicho, es posible afirmar que el "Trabajo Decente" es trabajo productivo

5 lbid.

6 Véase RODGERS, Gerry, El trabajo decente como una meta para la economía global, Boletín No. 153, Formación profesional, productividad y trabajo decente, Cinterfor, Montevideo, 2002, p. 14

7 Ibid. 
ejecutado en condiciones de libertad, equidad, seguridad y dignidad, en el cual los derechos son protegidos y que cuenta con remuneración adecuada y protección social.

Incluso, sería posible afirmar que el trabajo decente implica, además, oportunidades de trabajo productivo y con ingreso justo; brindar seguridad en el lugar de trabajo y protección social para los trabajadores y sus familias; mejores perspectivas para el desarrollo personal y para la integración social; dar a las personas la libertad de expresar sus opiniones, organizarse y participar en la toma de decisiones que inciden en sus vidas; $y$ tener la garantía de una igualdad de oportunidades y de trato para todos y todas.

Empero, para que lo anterior funcione es necesario que se garantice "(...) el respeto a los principios y derechos fundamentales en el trabajo reconocidos en los ocho convenios fundamentales de la OIT (...)" (sic) ${ }^{8}$, los cuales revelan y expresan las cuatro (4) dimensiones de la noción de "Trabajo Decente", las cuales a saber son las siguientes:

(i) Trabajo y empleo;

(ii) Derechos en el trabajo;

(iii)Previsión social; y

(iv)Diálogo social.

La primera dimensión está referida al trabajo propiamente dicho y al problema que representa el desempleo y sub-empleo mundial, y las precarias condiciones en las que muchas personas prestan servicios.

En este sentido, cabe apuntar que según datos de la OIT actualmente hay en todo el mundo ciento sesenta (160) millones de personas desempleadas; quinientos (500) millones de personas que perciben menos de US\$1.00 (UNO Y 00/100 DÓLARES AMERICANOS) diario como contraprestación por su trabajo, lo que resulta insuficiente para cubrir las necesidades básicas; y muchas otras que prestan servicios en jornadas extensas, ejecutando trabajos de poca productividad, temporales e informales.

Lo anterior revela la necesidad de crear oportunidades de empleo productivo que se pueda ejecutar en condiciones adecuadas. ${ }^{9}$

La segunda dimensión está referida al respeto de los derechos fundamentales, los cuales están contenidos en las normas laborales básicas de la OIT, las mismas que, sin embargo, han sido y son ampliamente incumplidas, como sucede por ejemplo en nuestro país.

La tercera dimensión está referida a la seguridad que se debe brindar para la prestación del servicio contratado.

Al respecto, podemos señalar que es un dato objetivo que muchas ocupaciones son inseguras, porque son irregulares o provisionales, porque no están adecuadamente remuneradas, porque exponen a quien las ejecuta a riesgo físico y enfermedades, etc.

La doctrina coincide en que "(...) la seguridad es una necesidad imperiosa, y puede lograrse de diversas maneras: a través de sistemas formales de seguro social que cubran eventualidades tales como enfermedad, desocupación o vejez; mediante mecanismos solidarios o mutuales; a través de inversiones preventivas en los lugares de trabajo; y mediante instituciones y politicas de mercado laboral que protejan a los obreros de las fluctuaciones del

8 HERNÁNDEZ PULIDO, Ricardo, Normas Internacionales del Trabajo y trabajo decente: El impacto de las normas internacionales del trabajo sobre el desarrollo económico y social sostenible. En: Les Normes Internacionales du Travail: un patrimoine pour l'avernir, OIT, Ginebra, 2004.

9 El trabajo decente puede significar también no tener que esforzarse excesivamente y la posibilidad de un retiro favorable. El concepto llega a una noción más amplia del lugar que le corresponde al trabajo en la vida del hombre: estar libres del trabajo excesivo es también una meta. Véase, RODGERS, Gerry, Ob. Cit., p. 15. 
empleo (legislación o convenios colectivos que desalienten el despido, por ejemplo, o sistemas de capacitación que permitan el reingreso al mercado de trabajo)" (sic). ${ }^{10}$

La cuarta dimensión está referida al diálogo social, esto es, a los mecanismos de comunicación que deben crearse entre los actores sociales, incluido el Estado, los cuales además de existir, deben ser fluidos y de resultados efectivos. $Y$ es que "(...) las formas en que la gente puede hacer oír su voz constituyen un aspecto esencial del trabajo decente" (sic). ${ }^{11}$

Lo anterior exige un esfuerzo de los trabajadores, quienes normalmente plantean el diálogo a través de la organización sindical; pero también de los empleadores, quienes también deben organizarse para facilitar el entendimiento entre las partes.

Un aspecto que merece la pena destacar de esta cuarta dimensión del "Trabajo Decente" es que puede permitiry/o lograr un importante apoyo para el desarrollo de las otras dimensiones.

Ciertamente, si en términos generales, los trabajadores se expresan mediante el sindicato, y el convenio colectivo es una expresión clara del diálogo social, no cabe duda que este (el convenio colectivo) ofrece una situación inmejorable para lograr el pago de una remuneración adecuada y el otorgamiento de mejores condiciones de trabajo.

En virtud de lo expuesto, resulta que cada una de las manifestaciones reseñadas presenta un enfoque o arista distinta de un mismo tema, por lo que debemos coincidir con quienes afirman que "(...) cada una de estas cuatro dimensiones del trabajo decente tiene sus características propias, pero todas están estrechamente interrelacionadas y patrocinan juntas metas societarias tales como la integración social, la erradicación de la pobreza y la realización individual" (sic). ${ }^{12}$

\section{Trabajo Decente y Pobreza}

En otro orden de ideas, es necesario también referirnos aunque de manera breve y puntual a la relación que se genera entre el "Trabajo Decente" y la pobreza o específicamente, con la eliminación de la pobreza.

Así pues, resulta necesario apuntar como punto de partida que aún cuando el "Trabajo Decente" pueda ser considerado como un mecanismo y/o estrategia de reducción de la pobreza, no es posible perder de vista que "el umbral de la pobreza como meta depende de los recursos sociales y económicos de las sociedades, de manera que tiene un componente relativo" (sic). ${ }^{13}$

En efecto, el diseño de políticas públicas orientadas y enfocadas en la generación de "Trabajo Decente" no asegura el logro de la finalidad propuesta, pues ello dependerá también de la voluntad política de un Estado necesaria para impulsar la ejecución de las referidas políticas y asumir el gasto que las mismas generan. Tan cierto es lo anterior, que el Estado peruano nos ofrece el mejor ejemplo, toda vez que a pesar del aporte y apoyo brindado por la OIT en la elaboración del Programa Nacional de Trabajo Decente 2004 - 2006, el avance en el tema es poco significativo.

Con relación a este tema, la OIT ha señalado que "en lo que hace a la pobreza, la filosofía prevaleciente es el derecho a la inclusión, en el sentido de la participación, protección, acceso a empleos decentes e ingresos dignos. Pero

10 RODGERS, Gerry, Ob. Cit., p. 16.

11 lbid., p. 16.

12 Ibid., p. 16

13 Ibid., p. 22. 
la concreción de ese derecho depende de las condiciones económicas previas, y para cumplir con esas condiciones hay que fortalecer las capacidades de los trabajadores y de los correspondientes sistemas de producción. Así pues, el logro de los derechos implica el desarrollo de la capacidad económica y social" (sic) (el subrayado es nuestro). ${ }^{14}$

Lo anterior revela que el "Trabajo Decente" no centra ni concentra sus acciones en los trabajadores formales, sino principalmente en los informales, que son los realmente afectados por la pobreza y por las carencias que se pretende resolver.

Luego, es claro que el ámbito de actuación del "Trabajo Decente" incluye a la sociedad en su conjunto, lo que determina que tenga una agenda que excede al tema de la pobreza, aunque debe reconocerse que existe un fuerte nexo con ella, pues solo superándola será posible la consecución de las metas trazadas por un programa de "Trabajo Decente".

Así pues, podemos cerrar este tema apuntando que "El trabajo decente en tanto estrategia de reducción de la pobreza va más allá de la economía informal. Reconoce la complejidad de la pobreza, sus múltiples dimensiones, y ofrece un enfoque integrado que puede dar respuesta a diversas necesidades" (sic). ${ }^{15}$

Y es que "(...) lo particular del trabajo decente es que constituye un enfoque conjunto del trabajo, el empleo y el progreso (...) de manera que promoverlo significa también cambiar la forma en que funciona la economía global, para que sus beneficios lleguen cada vez a más gente. El trabajo decente no es sólo un objetivo de desarrollo a nivel nacional, sino además un principio orientador para la economía mundial" (sic). ${ }^{16}$

\section{Naturaleza Jurídica}

Por último, para cerrar los aspectos conceptuales consideramos necesario plantear el tema de la naturaleza jurídica del concepto "Trabajo Decente".

En este sentido, cabe preguntarnos si es un principio de derecho, un derecho, o un concepto autónomo promovido por un organismo internacional.

Para dar respuesta a la interrogante planteada es preciso reconocer que estamos antes un concepto relativamente nuevo, que como bien señala el profesor Ermida es dinámico y está en constante cambio.

En este sentido, actualmente no existe una respuesta específica a la naturaleza jurídica del concepto de "Trabajo Decente", sino una respuesta ecléctica, según la cual estamos ante una nueva materia que es a la vez principio, derecho, política, programa, etc. La tarea planteada aun no está resuelta.

\section{LOS DERECHOS INESPECÍFICOS LABORALES Y SU RELACIÓN CON EL TRABAJO DECENTE}

Es un dato objetivo que aún hoy, nueve (9) años después de haberse creado y acuñado el concepto de "Trabajo Decente" se trata de un concepto preliminar y en construcción, de carácter integrativo y de contenido ético.

En efecto, se trata de un concepto que sigue enfrentando dificultades para perfilarse y para implementarse en políticas concretas, en cada país o región, dada la diversidad que se presenta en cada lugar.

14 Ibid., p. 22.

15 lbid., pp. 25 y 26.

16 Ibid., p. 26. 
$Y$ es que resulta harto complicado aplicar un concepto único de "Trabajo Decente" a distintos niveles y procesos de desarrollo.

En tal sentido, coincidimos con Gerry Rodgers cuando se pregunta si ¿hay un nivel uniforme de "Trabajo Decente", al que el mundo puede aspirar, o varia en el tiempo y el espacio? ${ }^{17}$

Para responder la interrogante planteada, debemos reconocer que al ser el concepto de "Trabajo Decente" uno en construcción y permanente cambio, se trata de un concepto que tiene un piso pero no un techo.

Así pues, "(...) por encima de ese limite inferior lo que percibimos como trabajo decente incluye derechos y principios universales, pero asimismo refleja los valores y posibilidades de cada sociedad. En ese sentido, constituye un objetivo móvil, una meta que evoluciona junto con las posibilidades de las sociedades, un umbral que se desplaza junto con el progreso económico y social" (sic). ${ }^{18}$

Lo anterior, nos revela y confirma que el concepto de "Trabajo Decente" es uno de los del tipo "dinámico", pues a pesar de tener pilares sobre los cuales se construye, su contenido es cambiante, pues no siempre alcanza a los mismos derechos, lo que es producto de las diferencias existentes entre las distintas sociedades que lo acogen, de sus distintas formas de ver las cosas y de las posibilidades de las mismas. Incluso de las diferencias existentes entre las personas que, en su momento y en determinados espacios, deben configurar y dar contenido al referido concepto.

En vista de lo expuesto, debemos concluir que el concepto de "Trabajo Decente" es cambiante y aún se encuentra en proceso de desarrollo.
En este sentido, es preciso mencionar que el referido concepto no puede ser ajeno al desarrollo de los derechos fundamentales laborales, los que a saber son de dos (2) clases: unos, los Derechos Fundamentales de la Persona del Trabajador y otros, los Derechos Fundamentales en el Trabajo.

La doctrina nos informa que entre los primeros podemos mencionar a los siguientes:

- El derecho a la igualdad y a la no discriminación;

El derecho al honor, a la intimidad personal y a la propia imagen;

- El derecho de reunión;

- El derecho al debido proceso y a la tutela jurisdiccional efectiva;

- La libertad ideológica y religiosa;

- La libertad de expresión; etc.

Tales derechos no son otros que aquellos a los que la doctrina laboral reconoce y califica como "derechos inespecíficos laborales", a los que nos referiremos mas adelante.

Entre los segundos podemos mencionar a los siguientes:

- La libertad sindical y el derecho a la negociación colectiva;

- La libertad de trabajo;

- El derecho a la igualdad y a la no discriminación en materia laboral; etc.

De lo anterior, resulta que tales derechos no son otros que los que la OIT identifica en su Declaración relativa a Principios y Derechos Fundamentales en el Trabajo ${ }^{19}$, como el núcleo "duro" de derechos mínimos que debe reconocerse a todo trabajador en cualquier relación laboral.

17 Véase RODGERS, Gerry, Ob. Cit., p. 19.

18 ibid., p. 19.

19 Al respecto, se señala que"(...) La Declaración contiene un preámbulo, el cuerpo del texto expuesto en cinco párrafos, y un anexo que traza el seguimiento de la Declaración, que es una parte integrante de la misma Declaración (...)". El preámbulo hace eco de las convicciones expresadas en la Constitución de la OIT y reafirma los principios y de- 
Volviendo sobre los primeros, la doctrina señala que los derechos laborales inespecíficos son " ( $(. .$.$) otros derechos constitucionales de$ caráciter general $y$, por ello, no especificamenté laborales (que) pueden ser ejercidos, sin embargo, por los sujetos de las relaciones de trabajo (los trabajadores, en particular) en el ámbito de las mismas, por lo que en tal caso adquieren un contenido o dimensión laborales sobrevenidos. Se produce una 'impregnación laboral' de derechos de titularidad general o inespecifica por el hecho de su ejercicio por trabajadores asalariados (también eventualmente por empresarios) a propósito y en el ámbito de un contrato de trabajo" (sic). ${ }^{20}$
En el mismo sentido, se señala que se trata de "(...) derechos que le vienen atribuidos por las normas no tanto en su condición de trabajador cuanto en su calidad de persona y que, sin embargo, se expresan en el marco de una relación laboral y se reivindican ante o frente al empresario o empleador; en otras palabras, son derechos adscritos con carácter general a todas las personas, pero que son ejercidos por quienes al tiempo son trabajadores. La conversión de estos derechos de libertad en verdaderos derechos fundamentales laborales adviene, así, por una doble y simultánea vía: por cuanto son trabajadores los sujetos a los que corresponde la titularidad del derecho y por cuanto el derecho se ejerce en una relación juridica laboral" (sic). ${ }^{21}$

rechos fundamentales que constan en ella como base para promover su aplicación universal. Introduciendo el significado particular de 'la garantía de los principios y derechos fundamentales en el trabajo', el preámbulo señala cómo éstos permiten a la gente'reivindicar libremente y en igualdad de oportunidades una participación justà en las riquezas a cuya creación han contribuido, así como la de desarrollar plenamente su potencial humano' (quinto párrafo del preámbulo). La competencia de la OIT para establecer y ocuparse de las normas internacionales de trabajo se recuerda en el preámbulo, así como su apoyo universal a la promoción de los derechos fundamentales en el trabajo como expresión de sus principios constitucionales. Para promover el establecimiento contemporáneo de la Declaración, el preámbulo se refiere a la situación de creciente interdependencia económica, a la necesidad de que la política económica y la política social sean elementos que se refuercen mutuamente de cara a crear un desarrollo con una base sólida, a la importancia de la creación de empleos y a la especial atención que debe concederse a los problemas de las personas con necesidades sociales especiales.

En esencia, el cuerpo de la Declaración recuerda las obligaciones reciprocas de los Estados Miembros de la OIT y de la misma Organización. El párrafo 1 de la Declaración recuerda la naturaleza voluntaria de la pertenencia a la OIT, y lo que la aceptación de la Constitución por parte de un Estado Miembro conlleva respecto a los principios y derechos establecidos en estos instrumentos (...). Sin enumerarlos, la Declaración se refiere a los 'convenios que han sido reconocidos como fundamentales dentro y fuera de la Organización'. El párrafo 2 establece la obligación de todos los Estados Miembros tanto si han ratificado o no el convenio en cuestión de 'respetar, promover y hacer realidad de buena fe y de conformidad con la Constitución, los principios relativos a los derechos fundaméntale que son objeto de esos convenios, es decir:

a) La libertad de asociación y la libertad sindical y el reconocimiento efectivo del derecho de negociación colectiva;

b) La eliminación de todas las formas de trabajo forzoso u obligatorio; la abolición efectiva del trabajo infantil; y

c) La eliminación de la discriminación en materia de empleo y ocupación'.

Cuando se adoptó la Declaración, siete Convenios eran considerados fundamentales; el Convenio sobre la libertad sindical y la protección del derecho de sindicación, 1948 (núm.87), el Convenio sobre el derecho de sindicación y de negociación colectiva, 1949 (núm. 98), el Convenio sobre el trabajo forzoso; 1929 (núm. 29), el Convenio sobre la abolición del trabajo forzoso, 1957 (núm. 105), el Convenio sobre la edad mínima, 1973 (núm. 138), el Convenio sobre igualdad de remuneración, 1951 (núm. 100) y el Convenio sobre la discriminación (empleo y ocupación), 1958 (núm. 111). Después se añadió el Convenio sobre las peores formas de trabajo infantil, 1999 (núm. 182), que fue adoptado en junio de ese año y entró en vigor el 17 de noviembre de 2000.

Véase, TREBILCOCK, A., Declaración de la OIT relativa a los principios y derechos fundamentales en el trabajo y su seguimiento. En: Las normas internacionales del trabajo en un enfoque global, OIT, Ginebra, 2001, pp. 19 y 20.

20 PALOMEQUE LÓPEZ, Manuel Carlos y ÁLVAREZ DE LA ROSA, Manuel, Derecho del Trabajo, Novena Edición, Centro de Estudios Ramón Aceres S.A., Madrid, 2001, pp. 147 y 148.

21 VALDES DAL RE, Fernando, Los derechos fundamentales de la persona del trabajador. En: Libro de Informes Generales, XVII Congreso Mundial de Derecho del Trabajo y de la Seguridad Social, Montevideo, 2003, pp. 45 y 46. 
De lo anterior, resulta que los derechos inespecificos no son otros que aquellos de titularidad de cualquier persona, esto es, aquellos que pueden ser ejercidos por cualquier persona, pero que al ser ejercidos por un trabajador adquieren un carácter laboral.

Al respecto, el destacado laboralista español Fernando Valdes Dal Re, refiriéndose a dichos derechos afirma que "(...) Son estos los derechos de la persona del trabajador, o si se prefiere, los derechos que corresponden al trabajador en su condición de persona" (sic). ${ }^{22}$ La claridad y precisión de la citada afirmación nos libera de la necesidad de formular apreciaciones $y / 0$ explicaciones complementarias.

Así pues, es también incuestionable que hoy ya no se discute si los derechos laborales imponen límites a los derechos fundamentales del empleador, antes bien, se discute cuáles son dichos límites. Es decir, se ha superado la negación total y absoluta de los derechos laborales inespecificos como derechos fundamentales de la persona del trabajador, para centrar la discusión en cuáles son o deberían ser los referidos límites.

En suma, se reconoce la existencia de los referidos derechos; y se reconoce que los mismos imponen límites al ejercicio del poder de dirección del empleador, por lo que hoy la discusión está concentrada en determinar el alcance de los referidos límites.

Con relación a esto último, se señala que "(...) El que se reconozca al trabajador frente al empleador el derecho a no ser discriminado en el empleo, a la consideración debida de su dignidad y al respeto de su intimidad y a sus demás derechos fundamentales significa interiorizar esos derechos en la relación contractual, imponer al empresario limites y obligaciones contractuales y un deber de sal- vaguarda de esos derechos que va más allá del respeto a los intereses económicos del trabajador, y que alcanza el de sus intereses y valores como persona y como ciudadano. Los derechos fundamentales como limite al ejercicio de los poderes empresariales llegan a operar, aligual que la buena fe, como cláusula general, incluso si el empresario no está sujeto por las normas a causas o procedimientos en su actuación, opera, si cabe, con más intensidad en tales casos (STC 90/1997) (...)". ${ }^{23}$

Así pues, creemos que hacer referencia al "Trabajo Decente" es hacer referencia a un conjunto de derechos, los mismos que pueden ser calificados de "fundamentales", y entre los que cabe contar a los que corresponden a la persona del trabajador y a los pura y estrictamente laborales.

Reforzando lo anterior, cabe señalar que si los trabajadores solo pueden ser personas naturales (el que la prestación personalisima de servicios sea un elemento esencial del contrato de trabajo asi 10 demuestra), y que no es posible desligary distinguir entre la persona humana y el trabajador, es necesario que se reconozca al trabajador la titularidad de todos los derechos fundamentales antes mencionados, esto es, los Derechos Fundamentales de la Persona del Trabajador y los Derechos Fundamentales en el Trabajo.

A mayor abundamiento, debemos apuntar que para la OIT el trabajo no es, ni puede ser considerado como una mercancía, luego, los trabajadores no son objetos con valor comercial, sino personas, y además titulares de una serie de derechos.

En tal sentido, debemos concluir que dentro del concepto de "Trabajo Decente" debe incluirse además de los derechos fundamentales en el trabajo, los Derechos Fundamentales de la Persona del Trabajador, esto es, los derechos laborales inespecificos.

22 Ibid., pp. 39.

23 RODRIGUEZ-PIÑERO, Miguel, Buena Fe y ejercicio de poderes empresariales. En: Revista Relaciones Laborales, No. 17, Setiembre, 2003, p. 10. 
Por lo expuesto, y a modo de reflexión final respecto de este punto, consideramos que es posible concluir que los Derechos Fundamentales Laborales, deben constituirse en mecanismos que permitan acompañar el progreso y desarrollo económico, sin perder de vista el progreso y desarrollo social.

Ciertamente, solo de esa manera se podrá garantizar la justicia social que anhelamos y una globalización que permita y favorezca el desarrollo de todos: desarrollo y crecimiento económico sobre la base de "Trabajo Decente".

\section{CONCEPTO DE "TRABAJO DECENTE" COMO SUSTENTO DE LAS RESOLUCIONES EMITIDAS POR EL TRIBUNAL CONSTITUCIONAL}

Para referirnos al rol desempeñado por el concepto de "Trabajo Decente" en el sustento de las resoluciones emitidas por el Tribunal Constitucional es preciso hacer lo propio con lo que ha sucedido en nuestro Poder Judicial.

Ciertamente, para revisar y analizar cuán importante ha sido el referido concepto en la construcción de los pronunciamientos del Tribunal Constitucional es necesario hacer lo mismo con lo sucedido en nuestros Juzgados Especializados en lo Laboral, en las Salas Laborales de las Cortes Superiores y en la Sala de Derecho Constitucional y Social de la Corte Suprema.

Así pues, debemos reconocer como dato objetivo que en las sentencias emitidas por los Juzgados Laborales y por las Salas de Trabajo no existe referencia al concepto de "Trabajo
Decente". Incluso, debemos también reconocer que las referencias a los Convenios OIT que han sido calificados por la Declaración de Principios y Derechos Fundamentales en el Trabajo, como reguladores de tales derechos ${ }^{24}$, son también casi inexistentes.

$Y$ es que resulta una tarea complicada hacer un análisis de la materia controvertida, de los argumentos de las partes, y adicionalmente, sustentar la solución al problema con referencia a normas internacionales, especialmente Convenios OIT, y en forma adicional con referencia a desarrollos teóricos y doctrinarios. Máxime, si las sentencias de las Salas Laborales tienen normalmente una (1) o dos (2) páginas.

Situación similar se aprecia con las sentencias emitidas por la Sala de Derecho Constitucional de la Corte Suprema de Justicia de la República.

Ciertamente, de la revisión de las sentencias emitidas por las distintas instancias de nuestro Poder Judicial solo es posible advertir referencias a nuestra legislación interna, y un análisis eminentemente pragmático, lo que podría no resultar deseable, pues el hecho de ser práctico no necesariamente está reñido con el hecho de ser analítico.

No se pretende que las sentencias emitidas sean "piezas" teóricas y que contengan nuevos desarrollos doctrinarios, sino que sean pronunciamientos que incorporen, cuando sea necesario, referencias a normas internacionales y desarrollos teóricos que enriquezcan la resolución judicial.

24 El Perú ha ratificado los ocho (8) Convenios fundamentales de la OIT, los cuales combaten el trabajo forzoso e infantil y promueven la igualdad laboral, la libertad sindical y la negociación colectiva y a saber son los siguientes:

1. Convenio 29, Sobre el trabajo forzoso (1929)

2. Convenio 87 , Sobre la libertad sindical y la protección del derecho de sindicación (1948)

3. Convenio 98 , Sobre el derecho de sindicación y de negociación colectiva (1949)

4. Convenio 100, Sobre la igualdad de remuneración (1951)

5. Convenio 105, Sobre la abolición del trabajo forzoso (1957)

6. Convenio 111, Sobre la discriminación en el empleo (1958)

7. Convenio 138, Sobre la edad mínima de admisión al empleo (1973)

8. Convenio 182 , Sobre la prohibición de las peores formas de trabajo infantil y la acción inmediata para su eliminación (1999) 
A mayor abundamiento, no debe perderse de vista que la jurisprudencia como la doctrina, es una fuente de derecho, y como tal debería contribuir a crear derecho y no solo a resolver conflictos jurídicos.

Ahora bien, entrando al tema que nos interesa debemos señalar que por tratarse de un concepto nuevo y aún en desarrollo, en los pronunciamientos emitidos por nuestro Tribunal Constitucional no abundan las referencias al concepto de "Trabajo Decente", aunque si -no de manera importante por cierto- a los Convenios OIT que regulan los derechos que dan contenido al citado concepto.

Así pues, cabe apuntar que de una revisión de más de veinte (20) sentencias emitidas por el Tribunal Constitucional en materia laboral, y desde el año 2000, solo hemos encontrado referencias al concepto de "Trabajo Decente" en cuatro (4) de ellas.

La primera, es aquella contenida en la Resolución No. 4635-2004-AA/TC, de fecha 17 de abril del año 2006, en los seguidos por el Sindicato de Trabajadores de Toquepala y Anexos contra la empresa Southern Perú Copper Corporation, sobre jornadas de trabajo en el sector minero.

En el Fundamento 36 de la referida sentencia se señala que "(...) La jornada laboral de doce horas para los trabajadores mineros tampoco es compatible con el concepto de trabajo decente adoptado por la Organización Internacional del Trabajo desde hace varios años y que, en palabras de su Director General, consiste en promover oportunidades para que las mujeres $y$ los hombres obtengan el trabajo decente $y$ productivo, en condiciones de libertad, equidad, seguridad y dignidad humanas. Por ello, las normas, principios y derechos fundamentales del trabajo establecen criterios que definen elementos esenciales del trabajo decente (...)" (sic) (el subrayado es nuestro).

La segunda, es aquella contenida en la Resolución No. 00027-2006-PI/TC, de fecha 21 de noviembre del año 2007, en la acción de inconstitucionalidad iniciada por el Colegio de
Abogados de lca contra el artículo 7 de la Ley 27360, Ley de Normas de Promoción del Sector Agrario.

En el Fundamento 28 de la citada sentencia se señala que "(...) A manera de ilustración, debemos señalar que la OIT ha incluido como parte de sus políticas en áreas específicas de intervención-como es el caso del sector rural $y$ desarrollo local (sector que recibe un tratamiento propio)- esbozadas como parte integrante de la Agenda Hemisférica de Trabajo Decente para las Américas, 2006-2001 (...)" (sic) (el subrayado es nuestro).

La misma Resolución en su Fundamento 42 señala que "(...) Una de las metas centrales planteadas por la OIT es lograr un trabajo decente para todos, incluyendo el sector agricola en particular. Asi, destaca la OIT: "Trabajo decente implica la aspiración de cada hombre yde cada mujer, esté donde esté, de realizar un trabajo productivo en condiciones de libertad, equidad, seguridad y dignidad. El Trabajo Decente engloba el respeto de los derechos fundamentales, el acceso al empleo, la seguridad y la salud en el trabajo y la existencia de seguridad social. El Trabajo Decente es un resultado del diálogo social (...)" (sic) (el subrayado es nuestro).

Adicionalmente, la referida Resolución señala en su Fundamento 51 que "(...) en el marco de una Economía Social de Mercado, corresponde a la empresa o inversionista privado asumir el compromiso social-como contrapartida o balance a las inequidades que el propio mercado puede generar-, pues si bien es al Estado al que corresponde intervenir mediante la generación de políticas que velen por el bienestar de la población cuando ello sea necesario, no es menos cierto que los agentes económicos asumen también cierto nivel de compromiso de colaboración y manifestación de voluntad para que la población incremente sus estándares de vida en diversos aspectos, y uno de ellos es-sin duda alguna-la mejora progresiva de sus salarios y de las condiciones de trabajo. No basta, entonces con generar puestos de trabajo, sino que corresponde, además, pro- 
porcionar una plataforma minima de trabajo decente (...)" (sic) (el subrayado es nuestro).

La tercera es aquella contenida en la Resolución No. 04331-2008-PA/TC, de fecha 12 de setiembre del año 2008, en los seguidos por el señor Raúl Alfredo Salazar Cosio y otros contra el Ministerio de Relaciones Exteriores, sobre acceso al trabajo.

En el Fundamento 8 de la referida sentencia se señala que "(...) El derecho a la promoción en el empleo en igualdad de condiciones tiene su fundamento constitucional en el derecho al trabajo, entendido como un medio de realización de la persona (artículo 22) y en el principio-derecho de igualdad de trato y de oportunidades en la relación laboral (artículo 26). Mediante este derecho se trata de dar opción, sin preferencias ni discriminaciones, a los trabajadores que se encuentran en una misma situación para que puedan acceder en igualdad de condiciones a la promoción profesional, contribuyéndose de este modo a la realización y el desarrollo del trabajador, y a la configuración del trabajo decente" (sic) (el subrayado es nuestro).

La cuarta es aquella contenida en la Resolución No. 05652-2007-PA/TC, de fecha 6 de noviembre del año 2008, en los seguidos por la señora Rosa Bethzabe Gambini Vidal contra la Sociedad de Beneficencia de Lima Metropolitana, sobre despido por discriminación.

En los Fundamentos 36 y 37 de la referida sentencia se señala que "(...) La discriminación en el entorno laboral es un fenómeno social cotidiano y universal que provoca desigualdades entre las personas y genera desventajas sociales y económicas que debilitan la cohesión y la solidaridad sociales. Por ello, la erradicación de la discriminación laboral tiene por finalidad promover la igualdad de oportunidades a fin de que tanto hombres como mujeres disfruten de un trabajo decente, sin perjuicio de su origen, sexo, raza, color, orientación sexual, religión, opinión, condición económica, social, idioma, o de cualquier otra indole (...)" (sic) (el subrayado es nuestro).
De la revisión y análisis de la parte pertinente de las sentencias transcritas, se advierte que el Tribunal Constitucional conoce el concepto de "Trabajo Decente" -lo que resulta de singular importancia- y que ha hecho referencia a su contenido, y que incluso, se ha atrevido a incorporar en el catálogo de derechos que incluye, al de promoción y ascenso en el empleo, lo que podemos considerar una innovación teórica, pues hasta donde he investigado la doctrina no ha incluido en el catálogo de derechos que incluye el "Trabajo Decente", a aquel que corresponde al ascenso.

Dicho esto, no queda sino por apuntar dos (2) consideraciones finales. La primera, que esperamos que la referencia al citado concepto y/o a los Convenios OIT que regulan los derechos que incluye, garantiza y protege, sea cada vez frecuente.

La segunda, que sería deseable que el Tribunal Constitucional construyera un concepto práctico y mínimo de lo que debe considerarse "Trabajo Decente".

Desarrollando lo anterior, cabe apuntar que en nuestra opinión, no basta con hacer referencia al concepto y contenido teórico, sino que es necesario darle contenido propio, práctico y real, pues no todas las realidades y legislaciones laborales son iguales. Ciertamente, pues lo que para el Perú es trabajo decente, puede no serlo para Chile o Canadá, máxime, si lo que para el Perú es trabajo decente, para China-de hecho- no lo es.

Además, si ya hemos dicho que el concepto de "Trabajo Decente" tiene un piso y no un techo, en nuestra opinión resulta importante poder contar con un contenido mínimo de "Trabajo Decente", el mismo que podrá ser ampliado, ajustado y adaptado al caso concreto cada vez asi sea necesario.

\section{EL TRATAMIENTO DE LA JORNADA DE TRABAJO EN LA JURISPRUDENCIA DEL TRIBUNAL CONSTITUCIONAL}

Como ya ha quedado dicho, el "Trabajo Decente" es un trabajo productivo, con reconocimiento 
de derechos y con protección social, esto es, trabajo que se genera basado en el principio de causualidad (a plazo indefinido o temporal); que se ejecuta en una jornada razonable; que se remunera de manera adecuada; que reconoce derechos (a horas extras, descanso semanal, vacaciones, etc.); que se ejecuta en un ambiente de trabajo seguro y saludable; que se ejecuta con cobertura previsional y de salud; y que autoriza al ejercicio pleno de los derechos colectivos (sindicación, negociación colectiva y huelga).

De lo anterior, resulta necesario destacar que "Trabajo Decente" es, entre otros aspectos, aquel que se ejecuta en una jornada razonable y no en periodos de labor largos, prolongados y extenuantes.

Y no podía ser de otra manera, pues por lo menos en nuestro medio y en nuestra experiencia, la limitación de la jornada de trabajo fue uno de los primeros derechos laborales conseguido por la presión sindical. ${ }^{25}$ Lo anterior revela la importancia de su contenido y la necesidad de que forme parte del catálogo de derechos que forman parte del concepto "Trabajo Decente".

Antes de referirnos a lo señalado sobre el tema por parte del Tribunal Constitucional, conviene señalar que nuestra Constitución en su artículo 25 establece que "La jornada ordinaria de aprobada mediante Decreto Supremo del 15 de enero de 1919. (articulo 1572)" (sic). trabajo es de ocho horas diarias o cuarenta y ocho horas semanales, como máximo. En caso de jornadas acumulativas o atipicas, el promedio de horas trabajadas en el periodo correspondiente no puede superar dicho máximo (...)" (sic).

Por su parte, el articulo 1 del Texto Único Ordenado de la Ley de Jornada de Trabajo, Horario y Trabajo en Sobretiempo, aprobado por Decreto Supremo No. 007-2002-TR, dispone que "La jornada ordinaria de trabajo para varones $y$ mujeres mayores de edad es de ocho (8) horas diarias o cuarenta y ocho (48) horas semanales como máximo (...)" (sic).

A continuación, el artículo 2 del mismo texto normativo señala que el empleador tiene facultades para "(...) establecer jornadas compensatorias de trabajo de tal forma que en algunos dias la jornada ordinaria sea mayor $y$ en otras menor de ocho (8) horas, sin que en ningún caso la jornada ordinaria exceda en promedio de cuarenta y ocho (48) horas por semana $(. . .)^{\prime \prime}(\mathrm{sic})^{26}$

De la lectura de las disposiciones transcritas, es claro que en nuestro sistema de relaciones laborales la jornada máxima es ocho (8) horas diarias o cuarenta y ocho (48) horas semanales; y que en caso las jornadas sean atípicas, por

25 Al respecto, se afirma que"(...) En 1913 se dictó la primera ley de ocho horas que se aplicó para los trabajadores del muelle Dársena del Callao, luego de una fuerte presión de estos trabajadores por el establecimiento de una jornada máxima de trabajo. En 1919, una de las últimas normas laborales expedidas por el presidente Pardo, fue la Ley de las Ocho Horas,

Pese a la generalidad que podria importar su redacción o nombre, la Ley de las Ocho Horas tenia como marco subjetivo de aplicación únicamente a las empresas industriales, agrícolas, mineras, de transporte ferroviario y las obras públicas del Estado. Recién a partir del Código Civil de 1936 la jornada máxima de ocho horas se aplicó para todos los trabajadores

26 El articulo del Reglamento del TUO de la Ley de Jornada de Trabajo, Horario y Trabajo en Sobretiempo, aprobado por Decreto Supremo No. 008-2002-TR, establece que "El establecimiento de la jornada ordinaria máxima diaria o semanal no impide el ejercicio de la facultad del empleador de fijar jornadas alternativas acumulativas o atípicas de trabajo, de conformidad con el artículo 4 de la ley, siempre que resulte necesario en razón de la naturaleza especial de las labores de la empresa.

En este caso, el promedio de horas trabajadas en el ciclo o período correspondiente no podrá exceder los límites máximos previstos por la ley. Para establecer el promedio respectivo deberá dividirse el total de horas laboradas entre el número de dias del ciclo o periodo completo, incluyendo los dias de descanso" (sic).

Véase, TOYAMA MIYAGUSUKU, Jorge Luis, Instituciones del Derecho Laboral, Gaceta Juridica, Primera Edición, Lima, 2004, p. 25. 
acumulativas y compensatorias en ningún caso pueden superar el límite semanal antes mencionado.

No obstante lo anterior, es usual que en el sector minero, por el tipo de actividad realizada y por las condiciones en las que se ejecuta, las jornadas laborales sean-normalmente- atípicas, esto es, acumulativas y compensatorias.

Justamente, fue tal situación la que determinó la interposición de una acción de amparo por una organización sindical a efectos de que se respete la jornada máxima legal establecida en la ley.

Concretamente, nos estamos refiriendo a la acción de amparo correspondiente al Expediente No. 4635-2004-AA/TC, iniciada por el Sindicato de Trabajadores de Toquepala y Anexos contra la empresa Southern Perú Copper Corporation.

En dicho proceso, mediante Resolución de fecha 17 de abril del año 2006, el Tribunal Constitucional declaró fundada la demanda tras considerar, entre otros aspectos, que "(...) Lajornada laboral de doce horas para los trabajadores mineros tampoco es compatible con el concepto de trabajo decente adoptado por la Organización Internacional del Trabajo desde hace varios años y que, en palabras de su Director General, consiste en promover oportunidades para que las mujeres y los hombres obtengan el trabajo decente y productivo, en condiciones de libertad, equidad, seguridad y dignidad humanas. Por ello, las normas, principios y derechos fundamentales del trabajo establecen criterios que definen elementos esenciales del trabajo decente (...)" (sic) (el subrayado es nuestro).

De lo anterior, resulta claro e incontrovertible que el Tribunal Constitucional reconoce como expresión del "Trabajo Decente"la prestación de servicios en una jornada razonable y específicamente en una que no supere la máxima legal o excepcionalmente, que el promedio de horas trabajadas en un periodo de tres (3) semanas no exceda de cuarenta y ocho (48) horas, respetándose de ese modo los derechos reconocidos en la Constitución y en los Tratados Internacionales de Derechos Humanos. ${ }^{27}$

Lamentablemente, hasta donde se tiene conocimiento este es el único pronunciamiento del Tribunal Constitucional sobre el tema de jornada de trabajo, aunque por ello no deja de ser importante, pues además de establecer la prestación de servicios en una jornada razonable, crea un "test de seguridad", el mismo que debe ser aplicado para determinar en cada caso concreto si las jornadas de trabajo atípico establecidas en la actividad minera respetan o no el concepto de "Trabajo Decente" creado porla OIT.

\section{EL TRATAMIENTO DEL DERECHO DE IGUALDAD EN LA JURISPRUDENCIA DEL TRIBUNAL CONSTITUCIONAL}

Según lo que se ha explicado y desarrollado previamente, el derecho a la igualdad y a la no discriminación en materia laboral, es un derecho fundamental en el trabajo y como tal, una expresión del "Trabajo Decente".

En efecto, la eliminación de la discriminación en materia de empleo y ocupación y la necesidad de garantizar la igualdad de trato y de oportunidades son expresión del concepto de "Trabajo Decente".

Al respecto, cabe señalar que el numeral 2) del artículo 2 de la Constitución dispone que "Toda persona tiene derecho (...) A la igualdad ante la Ley. Nadie puede ser discriminado por motivo de origen, raza, sexo, idioma, religión, opinión, condición económica o de cualquier otra índole" (sic).

A su turno, el numeral 1) del articulo 26 del texto constitucional establece que "En la relación

27 Véase ROMERO MONTES, Francisco Javier, La acumulación de jornadas de trabajo. En: Revista Laborem, No. 6, Lima, 2006, p. 201. 
laboral se respetan los siguientes principios (...) Igualdad de oportunidades sin discriminación" (sic).

De la lectura de las disposiciones transcritas se advierte que la primera de ellas se refiere al derecho fundamental de la persona del trabajador a la igualdad ante la Ley; mientras que la segunda de ellas hace lo propio con el principio de igualdad, cuya manifestación en la relación laboral es la "igualdad de trato".

En otras palabras, y para utilizar la nomenclatura correcta, cabe apuntar que la primera de las normas bajo comentario se refiere a un derecho

Tal es el caso, por ejemplo, de la Resolución No. 05652-2007-PA/TC, de fecha 6 de noviembre del año 2008, emitida en el proceso de acción de Internacional del Trabajo, Lima, 2005, p. 43. amparo seguido por la señora Rosa Bethzabe Gambini Vidal contra la Sociedad de Beneficencia de Lima Metropolitana. En el referido proceso, la demandante afirma haber sido victima de un despido discriminatorio por su estado de gestación y reclama su reposición en el puesto de trabajo.

Siendo específicos, debemos señalar que en los Fundamentos 36 y 37 de la referida sentencia se señala que "(...) La discriminación en el entorno laboral es un fenómeno social cotidiano y universal que provoca desigualdades entre las personas y genera desventajas sociales y económicas que debilitan la cohesión y la solidaridad sociales. Por ello, la erradicación de la discriminación laboral tiene por finalidad promover la igualdad de oportunidades a fin de que tanto hombres como mujeres disfruten de un trabajo decente, sin perjuicio de su origen, sexo, raza, color, orientación sexual, religión, opinión, condición económica, social, idioma, o de cualquier otra indole (...)" (sic) (el subrayado es nuestro).

Reforzando lo anterior, cabe señalar que otras sentencias que presentan las mismas características son las siguientes:

(i) Resolución de fecha 11 de julio del año 2002, recaída en el Expediente No. 1124-2001-AA/ $T C$, en los seguidos por el Sindicato Unitario de Trabajadores de Telefónica del Perú S.A.A. y la Federación de Trabajadores de Telefónica del Perú (FETRATEL), sobre discriminación por afiliación sindical.

(ii) Resolución de fecha 19 de agosto del año 2002, recaída en el Expediente No. 0895-

28 Al respecto se señala que "(...) La Sala Transitoria Constitucional y Social de la Corte Suprema ha señalado que para que se configure la discriminación se deben presentar tres elementos:

a) Un hecho que establezca una distinción, exclusión o preferencia.

b) Un motivo determinante de dicha diferencia (raza, color, opinión, sexo, religión y otros).

c) El resultado objetivo de esta diferenciación de trato, que consistirá en la anulación o la alteración de la igualdad de oportunidades o de trato, en el empleo y la ocupación (...)" (sic).

Véase, CORTES CARCELEN, Juan Carlos, La aplicación de los principios y derechos fundamentales en el trabajo en el Perú en el contexto de la integración regional. Documento de referencia y conclusiones del seminario nacional sobre la aplicación de los principios y derechos fundamentales en el trabajo en el contexto de la integración regional, Oficina 
2001-APA/TC, en los seguidos por el señor Lucio Valentín Rosado Adanaque contra el Seguro Social de Salud (ESSALUD), Hospital Nacional Almanzor Aguinaga Asenjo, sobre discriminación por razones religiosas.

(iii) Resolución de fecha 4 de marzo del año 2004, recaída en el Expediente No. 217-2004-AA/ $T C$, en los seguidos por el señor Juan Luis Juliachs Berrios contra la Municipalidad Provincial de Tacna, sobre discriminación por discapacidad.

(iv) Resolución de fecha 31 de marzo del año 2004, recaída en el Expediente No. 25102002-AA/TC, en los seguidos por el señor José Andrés Vásquez y otros contra Telefónica del Perú S.A.A., sobre vulneración al principio de igualdad de oportunidades sin discriminación.

(v) Resolución de fecha 25 de junio del año 2004, recaída en el Expediente No. 0666-2004-AA/ TC, en los seguidos por la señora Leyda Mirella Rojas Injante contra la Empresa Municipal de Agua Potable de Alcantarillado de Ica (EMAPICA), sobre discriminación por estado de gestación.

(vi) Resolución de fecha 12 de agosto del año 2005, recaída en el Expediente No. 0082005-PI/TC, en los seguidos sobre acción de inconstitucionalidad por el señor Juan José Gorriti y otros contra la Ley 28175, Ley Marco del Empleo Publico, por la vulneración al principio de igualdad de oportunidades sin discriminación.

(vii)Resolución de fecha 5 de junio del año 2006, recaída en el Expediente No.01875-2006-PA/ $T C$, en los seguidos por el señor Víctor Ricardo Luna Mendoza y otros contra el Congreso de la República y el Ministerio de Relaciones Exteriores, sobre discriminación por edad.

Lo antes expuesto, sin lugar a dudas, a pesar de no hacer referencia expresa al concepto de "Trabajo Decente", si hace una referencia implícita, pues a nivel teórico existe unanimidad para reconocer que una de las finalidades del citado concepto es la erradicación de todas las formas de discriminación laboral.

\section{EL TRATAMIENTO DE LOS DERECHOS DE SINDICACIÓN Y NEGOCIACIÓN COLECTIVA EN LA JURISPRUDENCIA DEL TRIBUNAL CONSTITUCIONAL}

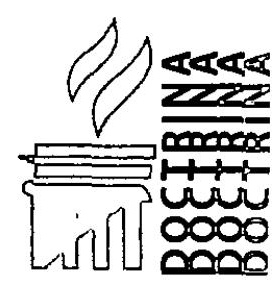

Como en el caso anterior, y según lo que se ha explicado y desarrollado previamente, la libertad sindical y la negociación colectiva, son derechos fundamentales en el trabajo y como tales, sendas expresiones del "Trabajo Decente".

Reforzando lo anterior, cabe señalar que la OIT en la Declaración relativa a Principios y Derechos Fundamentales en el Trabajo identifica a la libertad sindical y a la negociación colectiva como derechos especialmente protegidos y regulados por sendos convenios calificados de "fundamentales" y por ende, exponentes del concepto de "Trabajo Decente".

Al respecto, cabe señalar que los numerales 1) y 2) del articulo 28 de la Constitución señalan que "El Estado reconoce los derechos de sindicación, negociación colectiva y huelga. Cautela su ejercicio democrático.

\section{Garantiza la libertad sindical.}

2. Fomenta la negociación colectiva y promueve formas de solución pacifica de los conflictos laborales.

La convención colectiva tiene fuerza vinculante en el ámbito de lo concertado" (sic).

De la lectura de la disposición transcrita resulta inequívoco que nuestra Constitución reconoce como derechos esenciales $y$, por ende, fundamentales en el trabajo a la sindicalización y a la negociación colectiva.

En este caso, como en el anterior (referido al principio de igualdad y no discriminación), el Tribunal Constitucional no ha emitido un pronunciamiento en el que señale expresa y explícitamente que la vigencia de los derechos a la sindicación y a la negociación colectiva sean expresiones del "Trabajo Decente", lo que consideramos una tarea pendiente. 
Empero, lo que si ha hecho es emitir pronunciamientos en los que cita los Convenios 87 y 98 de la OIT, sobre la libertad sindical y la protección del derecho de sindicación, y sobre el derecho de sindicalización y de negociación colectiva, respectivamente.

Así, entre las sentencias que se refieren expresamente al Convenio 87 de la OIT, sobre la libertad sindical y la protección del derecho de sindicación, podemos mencionar a las siguientes:

(i) Resolución de fecha 5 de agosto del año 2002, recaída en el Expediente No. 632-2001AA/TC, en los seguidos por el Sindicato Unitario de Trabajadores de la Empresa Química del Pacifico S.A. contra la empresa Quimpac S.A. Paramonga, sobre sindicación, libertad sindical y protección de dirigentes sindicales.

(ii) Resolución de fecha 5 de enero del año 2006, recaída en el Expediente No. 3311-2005-PA/TC, en los seguidos por el Sindicato de Trabajadores Mineros de Atacocha contra la Compañía Minera Atacocha, sobre libertad sindical y protección de dirigentes sindicales.

Por su parte, entre las sentencias que se refieren expresamente al Convenio 98 de la OIT, sobre el derecho de sindicalización y de negociación colectiva, podemos mencionar a las siguientes:

(i) Resolución de fecha 26 de marzo del año 2003, recaida en el Expediente No. 0261 2003-AA/TC, en los seguidos por la Cámara Peruana de la Construcción (CAPECO) contra el Ministerio de Trabajo y Promoción del Empleo, sobre negociación colectiva.

(ii) Resolución de fecha 12 de octubre del año 2004, recaída en el Expediente No. 07852004-AA/TC, en los seguidos por COSAPI S.A. contra el Ministerio de Trabajo y Promoción del Empleo, la Cámara Peruana de la Construcción (CAPECO) y la Federación de Trabadores de Construcción Civil del Perú (FTCCP), sobre negociación colectiva articulada.

De la revisión de las sentencias mencionadas, se advierte - como en el caso anterior- que no obstante no existir referencia expresa al concepto de "Trabajo Decente", sí existe una referencia implícita al mismo, pues la OIT y la doctrina más especializada afirman y reconocen que una de las finalidades del citado concepto es la promoción de los derechos a la sindicalización y a la negociación colectiva, pues ellos permiten potenciar el diálogo social y desarrollar las otras dimensiones del "Trabajo Decente".

Sin embargo, sin dejar de reconocer la importancia de que el Tribunal Constitucional haga referencia directa a los Convenios 87 y 98 de la OIT, para sustentar la resolución de conflictos jurídicos internos, y de ese modo hacer referencia implícita al concepto de "Trabajo Decente" creemos también que es una tarea pendiente del referido tribunal identificar explícitamente a los derechos de sindicalización y negociación colectiva como expresiones del "Trabajo Decente" y además -como ya lo dijimos- construir un concepto mínimo de "Trabajo Decente".

\section{VIII.LAS OTRAS DIMENSIONES DEL TRABAJO DECENTE EN LA JURISPRUDENCIA DEL TRIBUNAL CONSTITUCIONAL}

De acuerdo a lo señalado en el marco teórico del presente trabajo, el concepto de "Trabajo Decente" tiene cuatro (4) dimensiones y ocho (8) Convenios OIT a los que el propio organismo internacional ha calificado de "fundamentales".

Con relación a ellos y no obstante haber sido ratificados por el Estado peruano, debemos señalar que no hay pronunciamientos sobre todos los aspectos relacionados con el "Trabajo Decente".

Así, por ejemplo, cabe mencionar que no se ha encontrado resoluciones en los que el Tribunal Constitucional se refiera a la eliminación del trabajo forzoso y a la abolición del trabajo infantil.

Al respecto, y con relación a la eliminación del trabajo forzoso, Juan Carlos Cortes, experto peruano sobre la materia, señala que "(...) No hemos encontrado resoluciones judiciales 
que traten este tema de manera frontal (...)" (sic). ${ }^{29}$

El mismo autor y con relación a la abolición del trabajo infantil afirma que "(...) No hemos encontrado información sobre casos concretos en los que se discuta o aplique los Convenios Internacionales. Esto puede deberse a la dificultad de los menores de edad de acceder a la justicia" (sic). ${ }^{30}$

Así pues, en virtud de las consideraciones expuestas en este capítulo como a lo largo del presente trabajo, es claro que el Tribunal Constitucional tiene una tarea pendiente con el concepto de "Trabajo Decente", la misma que esperamos pueda ser ejecutada en el corto plazo, aunque de manera progresiva, pues como ha quedado dicho, el referido concepto es aún un concepto en construcción.

\section{CONCLUSIONES}

En función de las consideraciones precedentemente expuestas podemos concluir lo siguiente:

(i) El concepto de "Trabajo Decente" es un concepto preliminar y provisional, en construcción, de carácter integrativo y de profundo contenido ético.

(ii) Desde una perspectiva práctica "Trabajo Decente" es aquel que se genera basado en el principio de causualidad (a plazo indefinido o temporal); que se ejecuta en una jornada razonable; que se remunera de manera adecuada; en el que se reconocen derechos ( $a$ horas extras, descanso semanal, vacaciones, etc.); que se ejecuta en un ambiente-de trabajo seguro y saludable; que se ejecuta con cobertura previsional y de salud; y que autoriza al ejercicio pleno de los derechos colectivos (sindicación, negociación colectiva y huelga). (iii) El concepto de "Trabajo Decente" presenta cuatro (4) dimensiones: trabajo y empleo; derechos en el trabajo; previsión social; $y$ diálogo social.

(iv) La doctrina no ha definido de manera exacta la naturaleza jurídica del "Trabajo Decente", $y$ ha señalado que se trata de un nuevo concepto que es a la vez principio, derecho, política, programa, etc.

(v) Dentro del concepto de "Trabajo Decente" debe incluirse además de los Derechos Fundamentales en el Trabajo, los Derechos Fundamentales de la Persona del Trabajador, esto es, los derechos laborales inespecíficos.

Lo anterior se sustenta en el hecho que muestra a los Derechos Fundamentales Laborales, como mecanismos que permitan acompañar el progreso y desarrollo económico, sin perder de vista el progreso y desarrollo social.

(vi) Por tratarse de un concepto nuevo y aun en desarrollo, en los pronunciamientos emitidos por nuestro Tribunal Constitucional no abundan las referencias al concepto de "Trabajo Decente", aunque si--no de manera importante por cierto- a los Convenios OIT que regulan los derechos que dan contenido al citado concepto.

Como consecuencia de lo anterior, de la revisión de más de veinte (20) sentencias emitidas por el Tribunal Constitucional en materia laboral, y desde el año 2000, solo se ha encontrado referencias al concepto de "Trabajo Decente" en cuatro (4) de ellas.

(vii)Consideramos que es una tarea pendiente del Tribunal Constitucional construir un concepto práctico y mínimo de lo que debe considerarse "Trabajo Decente". 
Ciertamente, no basta con hacer referencia al concepto y contenido teórico del "Trabajo Decente", sino que es necesario darle contenido propio, práctico y real, pues no todas las realidades y legislaciones laborales son iguales.

(viii)Reforzando lo anterior, cabe señalar que si el concepto de "Trabajo Decente" tiene un piso y no un techo, resulta importante poder contar con un contenido mínimo de "Trabajo Decente", el mismo que pueda ser ampliado, ajustado y adaptado al caso concreto cada vez que así sea necesario.

(ix) El Tribunal Constitucional solo ha emitido una sentencia sobre el tema de jornada de trabajo, la que resulta importante pues además de establecer que la prestación de servicios solo puede ejecutarse en una jornada razonable, crea un "test de seguridad", el mismo que debe ser aplicado para determinar en cada caso concreto si las jornadas de trabajo atípico establecidas en la actividad minera respetan o no el concepto de "Trabajo Decente" creado por la OIT.

(x) El Tribunal Constitucional no ha emitido pronunciamientos en los que señale expresa y explícitamente que la vigencia del derecho a la igualdad y eliminación de la discriminación en materia de empleo y ocupación es una expresión del "Trabajo Decente".

No obstante lo anterior, sí ha emitido algunos pronunciamientos en los que analiza y revisa la protección de un trabajador contra un despido motivado por un acto de discriminación, lo que puede ser considerado como un pronunciamiento jurisdiccional que recoge y expresa el concepto de "Trabajo Decente".

(xi)El Tribunal Constitucional no ha emitido pronunciamientos en los que señale expresa y explicitamente que la vigencia de los derechos de sindicalización y de negociación colectiva son expresión del "Trabajo Decente".

Empero, de la revisión de algunas sentencias se advierte que no obstante no existir referencia expresa al concepto de "Trabajo Decente", sí existe una referencia implícita al mismo, pues la OIT y la doctrina más especializada afirman y reconocen que una de las finalidades del citado concepto es la promoción de los derechos a la sindicalización y a la negociación colectiva, pues ellos permiten potenciar el diálogo social y desarrollar las otras dimensiones del "Trabajo Decente".

(xii)Es importante que el Tribunal Constitucional haga referencia directa a los Convenios 87 y 98 de la OIT, para sustentar la resolución de conflictos jurídicos internos, sin embargo, creemos que es una tarea pendiente del referido tribunal identificar explicitamente a los derechos de sindicalización y negociación colectiva como expresiones del "Trabajo Decente". 